\title{
GRUPO DE ATIVIDADES ESTRUTURADAS COM ESTUDANTES: IDENTIFICAÇÃO DE VIOLÊNCIA NO AMBIENTE ESCOLAR
}

\author{
GROUP OF STRUCTURALIZED ACTIVITIES WITH STUDENTS: \\ IDENTIFICATION OF VIOLENCE IN THE SCHOOL ENVIRONMENT
}

*Zeyne Alves Pires Scherer, **Edson Arthur Scherer, ***Silvia Antunes Cocenas, ****Amanda Secco Gregorio

\section{RESUMO}

Na Escola Estadual Professora Glete de Alcântra é desenvolvido um projeto de extensão que objetiva investir na promoção da saúde física, mental e social discente. São oferecidas atividades estruturadas: jogos, dinâmicas e vivências grupais. Neste estudo apresentamos os resultados de três encontros grupais realizados com vinte alunos do $6^{\circ}$ ano do Ensino Fundamental. Os objetivos foram: verificar a opinião dos estudantes sobre a escola e os papéis de pessoas significativas; identificar conflitos existentes nestes alunos, segundo a tipologia dos atos violentos. A pesquisa qualitativa foi do tipo observação participante. A percepção dos alunos sobre a escola e os profissionais que fazem parte dela foi divergente. Consideraram os familiares como pessoas importantes, cuidadoras, que impõem limites, xingam e batem. Tiveram dificuldades em estabelecer seu papel e o dos colegas na escola; os colegas são amigos para brincar. Os tipos de violência identificados foram física, psicológica e negligência. Trabalhar autoestima, tolerância e cooperação; aliviar conflitos com atitudes afetuosas que expressem respeito; oferecer espaços educativos onde os jovens possam se posicionar, facilitar seu entrosamento e exercitar sua criatividade e reflexão colaboram preventivamente com a diminuição da violência na escola. Assim, facilita-se a construção de modelos de convivência pacíficos em outros ambientes sociais.

Palavras-chave: Estudantes. Escolas. Violência.

\footnotetext{
* Enfermeira, professora doutora da Escola de Enfermagem de Ribeirão Preto da Universidade de São Paulo (EERP-USP), líder do Grupo de Estudos Interdisciplinar Sobre Violência (GREIVI), Centro Colaborador da OMS para o desenvolvimento da pesquisa em Enfermagem - Av. Bandeirantes, 3900 - Ribeirão Preto - SP - I4040-902 - e-mail: scherer@eerp.usp.br. ** Médico psiquiatra, professor doutor do Centro Universitário Barão de Mauá, Hospital das Clínicas da Faculdade de Medicina de Ribeirão Preto (HC-FMRP-USP), líder do GREIVI - e-mail: eascherer@hcrp.fmrp.usp.br. **** Terapeuta ocupacional, aluna do Programa de Pós-graduação em Enfermagem Psiquiátrica, HC-FMRP-USP, integrante do GREIVI - e-mail: silcocenas@yahoo.com.br. **** Graduanda do curso de bacharelado em Enfermagem da EERP-USP, bolsista do programa Aprender com Cultura e Extensão, integrante do GREIVI - e-mail: amanda.gregorio@usp.br.
} 


\section{ABSTRACT}

In the State School Professora Glete de Alcântra is developed an Extension' Project that objective to invest in the physical, mental and social health promotion of the pupils. Structuralized activities are offered: games, dynamic and group experiences. In this study we present the results of three group meeting carried through with twenty pupils of $6^{\circ}$ year of Basic Education. The objectives had been: to verify the opinion of the students on the school and the papers of significant people; and to identify existing conflicts in these pupils, according to the violent acts typology. Qualitative research, participant observation form. The perception of the pupils on the school and the professionals who were part of it had been divergent. They had considered family as important people, caregivers that impose limits, scold and beat. They had difficulties in establishing its paper and of the colleagues in the school. The colleagues are friends to play. Types of violence identified: physics, psychological and carelessness. To work self-esteem, tolerance and cooperation; to relieve conflicts with affectionate attitudes that express respect; to offer educative spaces where the youngest can talk, to facilitate its integration and to exercise their creativity and reflection collaborate preventively with the reduction of the violence in the school. Therefore, the construction of pacific models of together living in other social environments is facilitated.

Key words: Students. Schools. Violence. 


\section{INTRODUÇÃO}

A escola como uma instituição social, possuidora de objetivos e metas determinadas, é um espaço capaz de reelaborar conhecimentos socialmente produzidos e de permitir o exercício da ética e da razão. Portanto, é esperado que seja um local saudável, propício ao aprendizado, um ambiente solidário que garanta o direito à educação, independentemente das diferenças individuais [3, II]. Entretanto, esta mesma instituição, vista como um espaço multicultural, que abrange laços afetivos e prepara o indivíduo para a inserção na sociedade, reúne também diversos conhecimentos, atividades, regras e valores que são permeados por conflitos, brigas, invasões, depredações e, até mesmo, morte [II]. A diferente interação, contínua e complexa, que podemos encontrar no meio acadêmico pode ser reflexo da grande quantidade de pessoas com diferentes características que ali convivem.

Um dos problemas encontrados, portanto, nas instituições de ensino é a violência. Esta violência é categorizada pela Organização Mundial da Saúde (OMS) como interpessoal comunitária [9]. É entendida como toda ação de maus-tratos praticada, isolada ou em grupo, dentro destes estabelecimentos ou em suas redondezas. São protagonizadas pelos jovens com o envolvimento direto de alunos e outros atores como professores, funcionários, pais, entre outros [I].

No Relatório Mundial sobre Violência e Saúde da OMS [9] a violência foi classificada, quanto à natureza dos atos violentos, em física, sexual, psicológica e envolvendo privação ou negligência. Conhecer a natureza dos atos violentos, a relevância dos ambientes onde estes ocorrem, a relação entre o perpetrador e a vítima e as possíveis motivações, mostram-se como ferramentas para melhor compreender a complexidade do fenômeno violência.

O tipo de violência mais registrado ou praticado pelos jovens é a física, caracterizada pelo uso de força ou atos visíveis (brigas, agressões físicas, depredações) praticados entre alunos, ou membros da escola portando facas, revólveres ou outros objetos. Outra forma comumente encontrada nas escolas é a violência verbal, manifestada sob a forma de xingamentos e uso de palavras de baixo calão entre os próprios alunos dentro e fora da instituição. A violência simbólica, discriminação praticada por alunos e/ou membros da escola e o bullying, manifestado por ofensas verbais, apelidos ofensivos e depreciativos, humilhação, exclusão e discriminação, completam a lista de violências presentes nas escolas [4, 5, II, I3] .

Estas manifestações de violência podem ser reflexo de fatores externos e, como consequência, têm gerado conflitos dentro do ambiente escolar, comprometendo o aprendizado e as relações interpessoais entre educadores e educandos. Os relacionamentos ou vínculos são construídos entre as pessoas na convivência grupal. O grupo pode ser considerado como um espaço de trocas interativas, importante para o desenvolvimento psicológico do ser humano. Favorece a exploração da subjetividade ao atuar como um "laboratório social" no qual os participantes reproduzem os papéis que ocupam no seu cotidiano [6,I6].

Por conseguinte, tendo constatado que as relações estabelecidas dentro da escola se dão por meio de grupo, iniciamos em 2009 o projeto de extensão Grupos de atividades estruturados com alunos do ensino fundamental: promoção de saúde. Este projeto faz parte das múltiplas ações de cultura e extensão da Pró-Reitoria de Cultura e Extensão Universitária da Universidade de São Paulo. O objetivo do projeto é oferecer conjuntos de atividades estruturadas (pintura, desenhos, esculturas, música, teatro, jogos, dinâmicas e vivências grupais) para trabalhar a autoestima, a tolerância e a cooperação entre estudantes do ensino fundamental; instrumentalizar os alunos de enfermagem para que se tornem agentes transformadores na implementação de estratégias educativas promotoras de aprendizagem, saúde, socialização e cidadania.

O referido projeto é desenvolvido na Escola Estadual Professora Glete de Alcântra (EEPGA), localizada no distrito oeste do município de Ribeirão Preto (SP). Esta instituição foi escolhida com base nos critérios a ela atribuídos pela Diretoria de Ensino, a saber: alta frequência de incidentes de violência; dificuldades na condução do processo de ensino-aprendizagem; grau de abertura da direção; disponibilidade e interesse dos professores para o desenvolvimento de pesquisas; coordenadores ou assistentes de direção atuantes, empenhados em promover ações de cidadania e cultura, além de organizar o vínculo da universidade com os professores [8].

Os sujeitos do projeto são alunos matriculados no $6^{\circ}$ ano do Ensino Fundamental da EEPGA. De um total de 230, distribuídos em sete salas, participam até IOO estudantes ao longo de um ano, distribuídos em cinco grupos compostos cada um de até vinte integrantes (alunos). O critério para a seleção e participação 
nestes grupos é aleatório. Para tanto, a partir da lista de frequência de cada turma é utilizada a progressão aritmética de razão três, contada a partir do primeiro nome desta lista. Quando algum dos selecionados não aceita participar do estudo são selecionados os estudantes em posição imediatamente posterior ou anterior da lista, respectivamente. São realizados oito encontros com duração de dois meses para cada grupo, com frequência semanal, duração de uma hora, em sala reservada e organizada para as atividades. Por sugestão da coordenação pedagógica da escola e para garantir a participação dos alunos neste projeto, os encontros grupais ocorrem de forma concomitante à segunda aula, sendo os participantes liberados para tal.

Estes grupos de atividades estruturadas são coordenados por duas estudantes de graduação em enfermagem da EERP-USP, uma voluntária e outra bolsista do Programa Aprender com Cultura e Extensão, com supervisão de uma terapeuta ocupacional, aluna de Pós-Graduação do Programa Enfermagem Psiquiátrica, e da coordenadora do projeto. No primeiro encontro grupal, os participantes são informados sobre o objetivo do grupo e é estabelecido o contrato ou o conjunto de regras que sustentarão o desenvolvimento do trabalho.

O objetivo das atividades grupais é oferecer um espaço onde os estudantes possam expressar sua criatividade e espontaneidade, experimentando novos ou antigos papéis de formas diferentes; resgatar sua autoconfiança, autoestima e percepção do seu próprio potencial; organizar visual e verbalmente suas experiências; fazer escolhas, e, com isso, tornarem-se sujeitos ativos da própria história e menos vítimas das circunstâncias externas. As regras de funcionamento são: a frequência ao grupo não será obrigatória; os participantes com $75 \%$ ou mais de presença receberão um certificado de "participação"; caso, por algum motivo, os estudantes não possam realizar um encontro, seus frequentadores serão avisados com antecedência; a data para o término do grupo é preestabelecida e será informada no primeiro encontro; cada encontro tem a duração de uma hora, com o horário predeterminado.

A cada encontro grupal é desenvolvida uma técnica estruturada de trabalho específica, escolhendose o tema relacionado com o grupo e com base em suas necessidades naquele momento. A utilização de diferentes estratégias e materiais justifica-se na possibilidade de explorar as diversas formas de criar, desenvolver e manifestar sentimentos, pensamentos e fantasias. O uso de atividades expressivas serve como recurso para estimular o diálogo entre os participantes, propiciando trocas e aprendizados significativos.

No decorrer do desenvolvimento deste projeto de extensão foram surgindo questionamentos como:

- Qual experiência, expectativa e/ou motivação este aluno tem para realizar uma atividade em grupo?

- Como cada aluno percebe o colega, o professor, o coordenador, o diretor, outros profissionais da escola e a si mesmo?

- Como o aluno lida com as diferenças que surgem no grupo?

- Como o aluno se comunica no grupo e fora deste (ambiente da escola, na família)?

Diante destas questões surgiu o interesse em aprofundar o estudo de conflitos que podem emergir em um grupo de estudantes que participam de atividades estruturadas.

\section{OBJETIVO}

- Verificar a opinião dos estudantes sobre a instituição escolar e os papéis de pessoas significativas na escola e na família.

- Identificar conflitos existentes em alunos do ensino fundamental participantes de atividades grupais, segundo a tipologia dos atos violentos.

\section{MÉTODO}

Pesquisa qualitativa na qual foi utilizada a observação participante para absorver a realidade do local do estudo por meio das anotações no diário de campo que buscou compreender aquilo que o sujeito não consegue expressar [I4].

Neste estudo foram apresentados os resultados referentes a três dos encontros grupais: o primeiro, o terceiro e o sétimo. Estes três grupos foram selecionados por contemplarem momentos diferentes do processo grupal (fase inicial, fase operacional e fase de término) desenvolvido junto aos estudantes, sujeitos desta pesquisa [Io].

Fizeram parte do estudo vinte alunos do $6^{\circ}$ ano, matriculados no ensino fundamental do ano letivo de 2010 que aceitaram participar do grupo de atividades 
do projeto de extensão. A faixa etária foi de IO a I3 anos.

Para coleta e acompanhamento das atividades foi criado um "Protocolo de Acompanhamento das Atividades Realizadas", preenchido por uma das pesquisadoras após cada encontro grupal. Este material serviu como instrumento para a supervisão do trabalho desenvolvido e como material de pesquisa. Foi utilizada a técnica de análise de conteúdo temática [I4] para analisar as três atividades grupais selecionadas para o estudo. Os nomes dos sujeitos apresentados nos resultados são fictícios.

O projeto de pesquisa foi analisado e aprovado pelo Comitê de Ética em Pesquisa da EERP-USP, mediante Protocolo n. II44/20IO. Os pais ou responsáveis pelas crianças que participaram do grupo de extensão assinaram termo de consentimento livre e esclarecido concordando com a participação dos mesmos na pesquisa.

\section{RESULTADOS E DISCUSSÃO}

No trabalho com grupos, o próprio grupo se torna um modelo de abstração da realidade e fonte de dados para análise e estudo. Contudo, o grupo como modelo é uma simplificação da realidade e dificilmente incluirá todas as variáveis dessa realidade [I5]. Nesta pesquisa, foi possível estabelecer uma analogia entre a realidade dos sujeitos e as atividades e interações propiciadas nos encontros grupais. Isto permitiu a compreensão de uma situação relativamente complexa que é a experimentada por estes alunos, que sofrem influências dos meios social, familiar e cultural nos quais se encontram inseridos.

Diante disto, o que encontramos foi um recorte de duas dessas representações.

\section{OPINIÕES SOBRE A ESCOLA E OS PAPÉIS DE PESSOAS SIGNIFICATIVAS}

Uma das atividades previstas no projeto tem como temática "como os alunos veem a escola". Nesta, os alunos deste estudo mostraram receio para se expressarem, preocupados com o destino de suas informações ou queixas. Para facilitar a realização da tarefa foi lembrado pelas coordenadoras do grupo que os encontros eram sigilosos (conforme contrato do grupo). A opinião de cada aluno sobre a escola e sobre aqueles que faziam parte dela, tanto no âmbito da administração quanto dentro das salas de aulas, foram divergentes. Ao mesmo tempo em que alguns participantes sabiam a importância da escola, outros a definiam como ruim. Isto foi evidenciado em atividade na qual deveriam definir a escola em uma palavra:



Quando foi solicitado que definissem os papéis de cada pessoa, considerada importante para eles, tanto da escola como da família, as definições foram variadas. A inspetora foi lembrada como uma figura de autoridade que repreende (verbal e fisicamente) e controla (entrada e saída, distribuição de merenda). Estes papéis atribuídos à profissional em questão podem gerar sentimentos de descontentamento, às vezes expressos de forma indireta como visto no comentário pejorativo de uma aluna:

- "Abre o portão." (Maria).

- "A pessoa que dá bronca, que dá suspensão." (Carlos).

- "Aquela que dá tapa na orelha." (Kátia).

- "A pessoa que olha os alunos durante o intervalo." (Carla).

- "A que organiza a distribuição da merenda, é aquela que tem uma função importante na escola.” (João).

- "A que tem cara de porca." (Rosa).

O professor recebeu definições relacionadas ao papel de educador e figura de autoridade na sala de aula:

- "A pessoa que ensina." (Carolina).

- "A pessoa que não deixa sair da sala." (Luisa).

- "A que educa." (Lais).

Em relação à diretora da escola, chamou a atenção o fato de que a maioria dos alunos disse que não a conhecia. Apenas um dos participantes a descreveu como aquela que é responsável por aplicar medida disciplinar: 
- "É ela quem dá suspensão.” (Carlos).

A coordenadora foi identificada como a pessoa que define o que os professores fazem, aquela que estabelece contato com os pais e que, de fato, administra a escola:

- "Liga na casa dos alunos." (José).

- "Falam o que o professor tem que fazer." (Rosa).

- "É quem manda fazer a comida." (Mario).

- "Fica no lugar da diretora, organiza a escola." (Carla).

Relacionaram seus familiares como pessoas importantes e presentes em suas vidas, que os cuidam, que são amigos, mas que também são responsáveis por impor limites ou mesmo xingar e bater quando não são obedecidos:

- "Mãe é aquela pessoa que te dá cintada quando você desobedece." (Rosa).

- "Pai é a pessoa que bate em você, trabalha para te cuidar, pra te dar comida." (Luisa).

- "Pai é aquele que não permite que namore." (Carolina).

- "Os irmãos são aqueles que batem em você todo dia, podem ser seus amigos ou inimigos, mas estão sempre perto de você." (Carlos).

Demonstraram, no entanto, dificuldades em estabelecer o papel deles, enquanto alunos, e o dos colegas dentro do contexto escolar. Percebem os colegas como amigos que estavam ali para brincar e se divertir:

- "Amigo é quem está com você todo dia." (Lais).

- "Aquele que brinca com você." (Mario).

Ao definir o que é um amigo uma das participantes relatou uma experiência que teve com uma das colegas fora da escola:

- "Eu e a Kátia fazemos parte de um núcleo e fomos para uma chácara apresentar um trabalho, quando voltamos pegamos carona com um moço que a gente não conhecia e a gente mexia com todo mundo na rua." (Carla).
Atitudes provocativas de pronunciar xingamentos, como a descrita acima, apareceram também ao longo do desenvolvimento das atividades realizadas, entre os participantes. Em alguns momentos, estudantes que não estavam participando do grupo atrapalhavam a atividade, pronunciando xingamentos e chutando a porta da sala. Estes comportamentos configuram atos de violência dos tipos psicológico (verbal) e físico.

A mudança de papéis sociais no contexto familiar levou à perda gradual da autoridade paterna e ao distanciamento da figura materna do núcleo familiar. Isto gerou uma ruptura do equilíbrio entre disciplina e afeto em relação aos filhos, consideradas funções fundamentais dos papéis parentais para a autodeterminação futura. Esta ruptura precoce pode criar carências que dificilmente serão compensadas na vida. A convivência com atos agressivos e com a competitividade, a rivalidade nos relacionamentos e o individualismo - resultante das sensações de abandono e rejeição - vão sendo assimilados pelos jovens e se configurando na representação social da violência - doméstica ou não como uma atitude de fuga e defesa [2].

Os resultados que se referem à observação de conflitos (violências) nos grupos objetos desta pesquisa estão apresentados na categoria a seguir.

\section{TIPOLOGIA DOS ATOS VIOLENTOS}

No início das atividades, mais especificamente no primeiro encontro, os alunos participantes trouxeram questionamentos referentes ao grupo e seu funcionamento. Perguntaram como seriam realizadas as atividades, por quanto tempo durariam os encontros e solicitaram aumento de frequência e duração de cada encontro:

- "Poderia ser todo dia?" (Rosa).

- "O que vamos fazer hoje? E semana que vem?” (Leila).

- "A gente poderia ficar mais tempo?" (Pedro).

Os questionamentos relativos à duração, frequência e funcionamento da atividade são esperados no início de qualquer trabalho em grupo com pessoas, independente de sua faixa etária. A solicitação de aumento de tempo de duração de cada encontro e da frequência dos mesmos pode ter sido influenciada pelo fato destes grupos ocorrerem em horário concorrente 
com o da grade escolar. Os alunos eram, como descrito no método, dispensados de um horário de aula para participarem desta atividade. A demonstração de interesse, curiosidade e expectativa pode sugerir, por outro lado, que o novo pode ser recebido como algo bom. A inquietação e a esperança, presentes em todos os momentos do trabalho com este grupo, foram percebidas como algo inusitado no ambiente escolar.

Em grupos estruturados podem ser observadas condições variáveis de "calor humano, tensão, movimentos, equilíbrio, restrições, alegria, insegurança e crises". Estas condições, em conjunto, formam a "atmosfera" grupal, responsável pelo que os participantes do grupo sentem a seu respeito [I5].

No grupo onde os estudantes emitiram suas opiniões acerca da EEPGA, foram encontradas as seguintes manifestações: que os alunos eram dispensados das aulas, tanto devido à reforma da estrutura física que estava sendo realizada, quanto pela falta de professores; que não são submetidos às avaliações escritas, com exceção de um simulado no final do semestre; que tem colegas que não sabem ler; que presenciam brigas nos intervalos e recreio; que alunos fumam na escola.

- "A escola está uma bagunça, muito ruim." (Carlos).

- "Faltam professores." (Laís).

- "Tem muita violência entre os alunos. Vou mudar de escola no próximo ano." (José).

- "Ele", referindo-se ao professor, "fica gritando com a gente, mandando a gente calar a boca, e até xingou minha mãe." (Maria).

- "Muito bagunçada, todos fumam." (Luisa).

- "Todos sabem de tudo o que se faz." (Pedro).

Estas falas são exemplos de formas de violência comuns e enraizadas na prática educativa. A omissão em prover as necessidades básicas para o desenvolvimento de uma pessoa, neste caso, a educação, caracteriza uma violência definida como privação ou negligência. Este é considerado um dos tipos mais sutis e de menor visibilidade dos atos violentos, mas não menos importante. Faz parte do dia a dia das escolas, caracterizando desde o poder coercitivo de imposição de conteúdos distantes do interesse e sem significado na vida dos alunos, a precariedade dos mesmos, a coação do poder de conferir notas, a desconsideração em relação às dificuldades dos estudantes, até tratamentos pejorativos e ações de exposição do aluno ao ridículo quando este não compreende o conteúdo ensinado, passando pela falta de professores [7]. Outros tipos de violência referidos pelos participantes deste estudo foram a verbal e a psicológica, praticados, também, pelos professores. Exemplo disto está na fala anterior, que mostra queixa do aluno de que um professor utilizou este "artifício" para disciplinar a sala de aula.

Nos três encontros, objetos deste estudo, os alunos participantes trocaram agressões de tipo físico (empurrões, jogar objetos uns nos outros) e verbal (xingamentos). Expressões como "cala a boca" e "idiota” eram frequentemente proferidos pelos alunos.

- "Garla", em tom bravo, "você molhou minha argila que eu ia levar". Em seguida, agrediu Carla com tapas e a xingou. "Sua chata e idiota!" (Katia).

- "Não quero mais participar do grupo", brava e jogando a argila em José, que a acusara de ter pegado sua argila. (Luiza).

- "O José está zoando da Carla por que ela não sabe escrever direito. Agora ela não quer mais fazer a atividade." (Carolina).

Durante os grupos foi perceptível a dificuldade de comunicação entre alguns participantes. Esta pode ser explicada, por exemplo, pela falta de simpatia entre os estudantes. Em quase todas as atividades, havia conflitos verbais decorrentes da deficiência de comunicação efetiva. $O$ material solicitado por um não era cedido pelo outro, o qual justificou não ter escutado tal pedido. As dificuldades de comunicação em casa podem, por sua vez, influenciar as dificuldades apresentadas no ambiente escolar. Quando alguns alunos eram questionados sobre o porquê de não pedirem o material emprestado, ou por que gritavam, justificavam dizendo que, em suas casas, era este o tratamento que recebiam.

Estas atitudes agressivas necessitaram da intervenção direta das coordenadoras do grupo no sentido de contê-las. Por terem ocorrido dentro do ambiente do grupo foi aberto um espaço para os estudantes conversarem sobre as mesmas, sua provável origem e consequências. Os participantes concordaram com o incômodo que tais atitudes trazem para o convívio, atrapalhando o desenvolvimento da própria atividade. Fizeram alusões a outras situações em que aparecem comportamentos violentos no contexto escolar e fora 
deste. Lembraram situação extrema de colega participante do grupo que acabou por abandonar a escola em função de ameaça séria de agressão feita por colega:

- "O Bruno, aquele que vinha no grupo, saiu da escola porque ele brigou com um menino e esse menino ameaçou o Bruno na hora do recreio com uma tesoura. Aí a mãe dele o tirou da escola." (Carolina).

No transcorrer das atividades grupais deste projeto de extensão, exemplificados na apresentação dos resultados de três destes encontros, tem sido possível perceber a existência de relacionamentos conflituosos na escola. Uma das formas de manifestação destes é o bullying, que evidencia a repercussão negativa da violência nas relações estabelecidas no ambiente escolar [II]. Jovens vítimas do bullying são geralmente indivíduos com dificuldades para suportar situações agressivas, retraindo-se, o que pode contribuir para a evasão escolar, já que, muitas vezes, não conseguem reagir à pressão a que são submetidos. Os pais e a escola, por sua vez, parecem não saber lidar com este tipo de violência, demonstrado nas dificuldades de agir frente a estas situações e em gerir a vida escolar.

Resultados de estudo comparativo entre alunos considerados agressivos e não agressivos de duas escolas identificaram em ambas a existência de relação entre agressividade na adolescência e ser vítima de punição física doméstica. Os jovens considerados agressivos na escola eram mais punidos do que os não agressivos [I2] No nosso estudo, uma aluna agressiva relatou situações em que era vítima de violência em sua casa. Em um dos encontros estudados, fez o relato a seguir:

- "Vou apanhar da minha mãe se chegar com a roupa desse jeito, suja de argila." (Kátia).

Não houve situação ou relato de violência sexual durante as atividades grupais objeto deste estudo.

A vulnerabilidade social refletida na vivência escolar, como a vista neste estudo, pode reduzir a força socializadora da escola, interferindo no ambiente relacional e permitindo que os alunos construam a violência como uma forma habitual de experiência escolar [3].

\section{CONCLUSÃO}

O fenômeno da violência que se expressa em instituições de ensino é resultante de modelos sociais e culturais, tanto do núcleo familiar primário, quanto do ambiente comunitário externo. Alguns tipos de violência são corriqueiros, até mesmo, aceitos na vida e comuns no contexto educacional. As instituições escolares convivem, portanto, com esta influência interna e externa de estressores e repressores sociais, representados pelos atos violentos. Os estudantes que participaram do nosso estudo identificaram a presença de violências do tipo física, psicológica e negligência no ambiente da EEPGA.

As ações desenvolvidas na e pela escola acabam, por vezes, contribuindo com a banalização ou legitimação da violência como mecanismo para resolver conflitos. Diante disto, é esperado que os estabelecimentos de ensino encontrem mecanismos para se configurarem como instituições de referência no combate a este fenômeno. Isto pode ser alcançado mediante a construção de um trabalho com ênfase em abordagens preventivas e que busquem preparar os jovens para o convívio em uma sociedade menos violenta.

Estratégias que objetivem trabalhar a autoestima, a tolerância e a cooperação entre estudantes do ensino fundamental podem ter efeito positivo. Os conflitos comuns a esta fase de vida (adolescência) podem ser aliviados com atitudes afetuosas que expressem respeito. A oferta de espaços educativos nos quais os jovens possam se posicionar, facilitar seu entrosamento com os colegas e exercitar sua criatividade e capacidade de reflexão colabora de forma preventiva com a diminuição da violência dentro do ambiente escolar. Desta forma, mediante a inserção e participação dos alunos na resolução de conflitos é facilitada a construção de modelos de convivência pacíficos reprodutíveis em outros ambientes sociais.

\section{REFERÊNCIAS BIBLIOGRÁFICAS}

[I] ABRAMOVAY, M.; RUA, M. G. Violências nas escolas. Brasília: UNESGO, 2002.

[2] BALISTA, G. et al. Representações sociais dos adolescentes acerca da violência doméstica. Revista Eletrônica de Enfermagem, v. 6, n. 3, p. 350-357. Disponível em: <http://www.fen.ufg.br/revista/revista6_3/O5_Original.html $>$. Acesso em: 25 ago. 20II. 
[3] GAMACHO, L. M. Y. Violência e indisciplina nas práticas escolares de adolescentes: um estudo das realidades de duas escolas semelhantes e diferentes entre si. São Paulo, 2000, 265 p. Tese (Doutorado), Faculdade de Educação, Universidade de São Paulo (USP).

[4] CHARLOT, B. A violência na escola: como os sociólogos franceses abordam essa questão. Sociologias, ano 4, n. 8, p. 432-43, 2002.

[5] FANTE, G. Fenômeno bullying: como prevenir a violência nas escolas e educar para a paz, 2. ed. Campinas: Verus, 2005.

[6] GUANAES, C.; JAPUR, M. Fatores terapêuticos em grupo de apoio. Rev. Bras. Psiquiatria, v. 23, n. 3, p. I34-I4O, $200 \mathrm{I}$.

[7] GUIMARÃES, A. M. A Escola e a ambiguidade. In: BORGES, A. S. et al. O papel do diretor e a escola de $\mathbf{I}^{\mathbf{0}}$ grau. Série Ideias, n. I2. São Paulo: FDE, I992, p. 5I-74.

[8] KODATO, S. Observatório da violência e práticas exemplares: vínculos e estratégias. Observatório da Violência, n. 22, 2003.

[9] KRUG, E. G. et al. World report on violence and health: summary. Geneva: World Health Organization, 2002.

[io] LASALLE, P. G.; LASALLE, A. J. Grupos terapêuticos. In: STUART, G.W.; LARAIA, M.T. Enfermagem psiquiátrica: princípios e prática. Porto Alegre: Artmed, 200I, p. 695-709.

[II] MARRIEL, L. C et al. Violência escolar e autoestima de adolescentes. Cadernos de Pesquisa, v. 36, n. 37, p. 35-50, 2006.

[i2] MENEGHEL, S. N.; GUIGLIANI, E. J.; FALCETO, O. Relações entre violência doméstica e agressividade na adolescência. Cadernos de saúde pública, v. I4, n. 2, p. 327-335, I998.

[i3] NETO; A. A.; SAAVEDRA, L. H. Diga NÃO para o bullying: programa de redução do comportamento agressivo entre estudantes. Rio de Janeiro: ABRAPI, 2004 .

[I4] MINAYO, M. G. S. O desafio do conhecimento: pesquisa qualitativa em saúde, 7. ed. São Paulo: HUCITEC; Rio de Janeiro: ABRASCO, 2000.

[I5] MOSCOVIGI, F. Desenvolvimento interpessoal: treinamento em grupo, 6. ed. Rio de Janeiro: José Olympio, I997.

[i6] SERrÃO, M.; BAlEeiro, M. G. Aprendendo a ser e a conviver. São Paulo: FTD, I999. 